The International Journal of
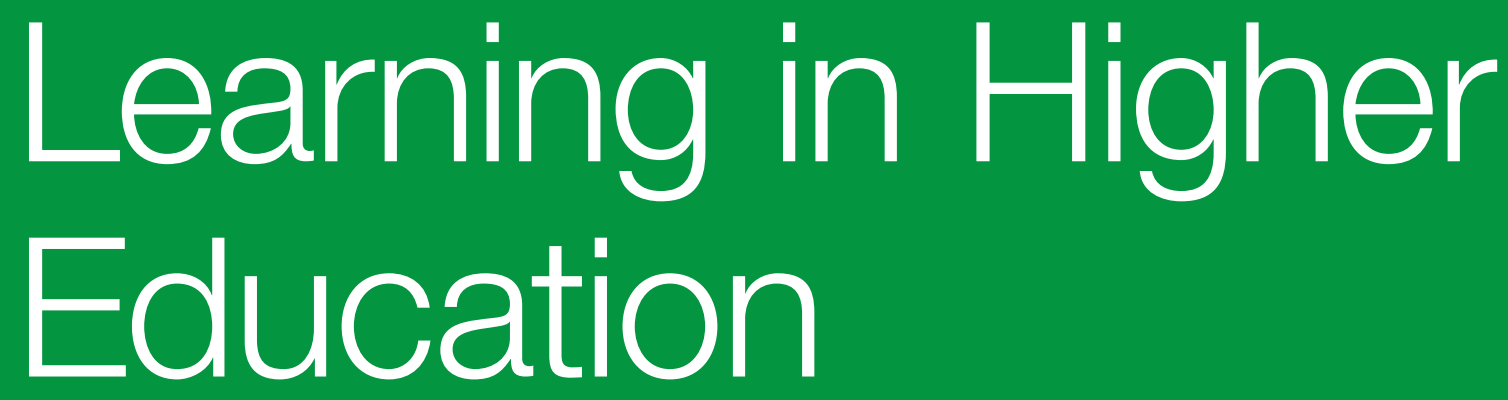

\title{
The First Year Experience
}

A Comparison of Institution Led Approaches to the Orientation and Engagement of First Year Students in Higher Education

STEPHEN ANTHONY LARMAR AND LYNN BURNETT 
THE INTERNATIONAL JOURNAL OF LEARNING IN HIGHER EDUCATION

http://thelearner.com/

First published in 2013 in Champaign, Illinois, USA

by Common Ground Publishing

University of Illinois Research Park

2001 South First St, Suite 202

Champaign, IL 61820 USA

www.CommonGroundPublishing.com

ISSN: ISSN Pending

(c) 2013 (individual papers), the author(s)

(C) 2013 (selection and editorial matter) Common Ground

All rights reserved. Apart from fair dealing for the purposes of study, research, criticism or review as permitted under the applicable copyright legislation, no part of this work may be reproduced by any process without written permission from the publisher. For permissions and other inquiries, please contact <cg-support@commongroundpublishing.com>.

The International Journal of Learning in Higher Education is a peer-reviewed scholarly journal.

Typeset in CGScholar.

http://www.commongroundpublishing.com/software/ 


\title{
The First Year Experience: A Comparison of Institution Led Approaches to the Orientation and Engagement of First Year Students in Higher Education
}

\author{
Stephen Anthony Larmar, Griffith University, Queensland, Australia \\ Lynn Burnett
}

\begin{abstract}
In the last decade increasing attention has been drawn to the successful orientation and engagement of first year students in higher education in Australia. Such attention has been influenced in part by growing concern with increasing student attrition across universities nationally. This concern has been shared internationally, with significant research being undertaken in the U.K. to determine cogent methods for engaging first year students in higher education. This paper reports on the work currently undertaken at Griffith University, Australia and four institutions based in the U.K., with a focus on institution-led approaches to the first year experience. Each institution's method of engaging and attending to the diverse needs of the first year cohort is discussed with a primary focus on common trends across each institution. First year student engagement data drawn from Griffith University is presented to lend support to the various initiatives examined.
\end{abstract}

Keywords: Higher Education, First Year Students, Orientation and Engagement, Retention, Attrition, Widening Participation

\section{INTRODUCTION}

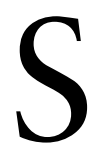

tudies focussing on the matriculation of students entering university emphasise the significance of the university environment in assisting student transition (Larmar \& Ingamells, 2010; McInnis \& James, 1995). The increasing focus on institution-wide approaches to better support first year students (Yorke \& Longden, 2008) has been influenced significantly by a widening participation agenda that has culminated in the massification of higher education both within Australia (Bradley, Noonan, Nugent, \& Scales, 2008; Nunan, 1999) and the U.K. (Kogan \& Hanney, 2000). With the dramatic increase in students entering universities internationally over the last decade, a more diverse student population has evolved, necessitating a shift in institutional responses to student cohorts that comprise individuals from different social and cultural backgrounds with varying needs and experiences (Kift, Nelson \& Clarke, 2010; McKenzie \& Schweitzer, 2001; Gabb \& Zhongjun, 2006). Historically, this increased elaboration of the student population correlates with a concerning rise in student attrition (Clarke \& Ramsey, Harris \& Palmer, 1995; 1990; Reay, 1998). Efforts to reduce attrition by attending to the diverse needs of first year students have culminated in extensive research and knowledge that has informed current theory and practice about first year student retention and engagement.

According to the literature, there are a number of key factors that influence first year student engagement in higher education (Burnett, 2006a; Kift, Nelson \& Clarke, 2010; Kift, 2008;

The International Journal of Learning in Higher Education

Volume 19, 2013, http://thelearner.com/, ISSN ISSN Pending

(C) Common Ground, Stephen Anthony Larmar, Lynn Burnett, All Rights Reserved, Permissions:

cg-support@commongroundpublishing.com 
Krause \& Coates, 2008; Pike \& Kuh, 2005). The level of preparedness for university is a primary predictor of the students' capacity to effectively engage with their studies and the broader university culture (Davies \& Elias, 2003; Krause, Hartley, James \& McInnes, 2005; Ozga \& Sukhnandan, 1998). This preparation is context-dependent and is influenced by the students' backgrounds and includes the personal resources they bring to the experience. Learning and teaching strategies that serve to engage students are also critical components that enhance the first year student experience (Burnett, 2007; Burnett \& Larmar, 2011; Larmar \& Ingamells, 2010; Lowe \& Cook, 2003; Tinto, 2002). Such approaches include those that are informed by a sound theoretical framework and provide a stimulating and meaningful experience that build upon the student's knowledge and previous life experiences. The development of relationships between the student and his/her peers and university personnel is another factor that influences student retention (Burnett \& Larmar, 2011; Kift, Nelson \& Clarke, 2010; McGivney, 1996; Wilcox, Winn \& Fyvie-Gauld, 2005). Students who develop sound social networks with their peers and supportive connections with faculty staff are more inclined to develop a sense of connection and belonging within the university environment that ultimately promotes successful engagement with learning. Motivation and a sense of capability is also a key indicator of student success (Burnett \& Larmar, 2011; Kift, Nelson \& Clarke, 2010; Lizzio \& Wilson, 2004: Ramsden, 2003). Students who feel more capable and have a strong motivation for the study they are undertaking are more likely to succeed. As a measure of enrolment, persistence, grades and attainment, success has been found to occur more frequently in students who, for a variety of reasons, are able to draw upon personal resources such as motivation and a sense of capability (Kuh, Kinzie, Buckley, Bridges, \& Hayek, 2006; McMillan, 2005; Pascarella \& Terenzini, 2005). The development and maintenance of a realistic study/life balance is also considered significant to student success (Kift, Nelson \& Clarke, 2010; McInnis \& Hartley, 2002). Students who are heavily burdened by commitments beyond their studies, such as excessive part-time work or carer responsibilities are less likely to effectively manage their time and complete academic tasks. Finally, a sense of connection to social support beyond the university environment is also considered to be of importance (Gerdes \& Mallinckrodt, 1994). Access to the support of family, friends and other social networks of significance is a significant factor to promote deeper engagement with university study (Pike \& Kuh, 2005). While each identified element works towards deeper engagement in the early learning environment, students' interaction in the learning process is accentuated when multiple positive factors are present (Kift, Nelson \& Clarke, 2010; Krause \& Coates, 2008; Pike \& Kuh, 2005).

\section{Institution-wide Approaches}

Given the importance of the variables identified above in influencing the retention and engagement of first year students, greater attention is being placed on institutional approaches that enhance the first year university experience in order to promote engagement. It is clear that an overarching consideration in the retention of first year students involves an institutional commitment to fostering a learning environment conducive to the retention and engagement of commencing students (Burnett \& Larmar, 2011; Kift, 2008; Krause \& Coates, 2008; Tinto, 2002).

This paper focuses on five institutions committed to the development of sound orientation and ongoing engagement practices that positively influence the first year student experience and ultimately aim to improve retention. More specifically, the paper reports on the work of four leading universities in the U.K., University College London (UCL), Leeds Metropolitan University, University of Manchester, and University of Brighton and provides an overview of key institution-wide strategies that serve to enhance the first year experience. Comparisons are drawn with Griffith University, Australia's institution-led approaches to deepening first year student engagement. Key data drawn from Griffith University is also presented that highlights 
the effectiveness of strategies that serve to enhance the first year experience. The overview of institution led strategies are based on a series of in-depth interviews with key academics drawn from each of the aforementioned universities who are working in strategically designated roles deemed instrumental to the widening participation of first year students within their local contexts. The following section provides an overview of the methodology adopted for the investigation.

\section{Method}

To examine institution specific first year engagement strategies across the institutions under investigation a mixed methodology approach was undertaken to access both qualitative and quantitative data. A sample of five universities was selected (including Griffith University, Australia-the first author is currently working as a Senior Lecturer in the School of Human Services and Social Work) to draw comparisons across each institution as a means of exploring common approaches to deepen first year student engagement.

\section{Sample}

The four U.K. institutions under investigation were selected on the basis of the following criteria as a means of identifying universities that shared common characteristics with the principal researcher's university of employment:

- Each attracts a diverse population of students, including individuals from disadvantaged backgrounds and individuals who are the first in family to access higher education;

- The institutions share a common focus on the development and implementation of a range of orientation and engagement strategies that provide ongoing support to students transitioning into the university environment;

- Key staff are employed within each university to assist in the oversight and ongoing maintenance of specific initiatives that serve to improve attrition across the student life-cycle;

- Geographical location-given the principal investigators limited time in the U.K. the geographical location of each institution was a key consideration to facilitate travel between each institution and to ensure that face-to-face interviews could be conducted within a limited time-frame.

\section{Universities Included in the Study}

Griffith University, Australia: Griffith University is a multi-campus public university situated in South East Queensland, Australia. The university's population of students comprises approximately 30, 000 with both undergraduate and post-graduate students enrolled across five campuses. Since 2002, Griffith University has focussed on the development of institution-wide practices and processes as a means of enhancing the first year experience. This focus was driven by the rising concern about increasing rates of attrition across Australian universities and its application for Griffith University as an institution with a strong agenda focusing on widening student participation.

University College London (UCL), U.K.: UCL is the largest college within the University of London. The college's main campus is based in Bloomsbury, London and consists of a community of over 27,000 staff and students. Academic and research personnel align with 72 departments within the institution and are engaged in productive research and industry partnerships both locally and internationally. The UCL student body is drawn from over 140 countries internationally with more than one third of the student community engaged in graduate studies. UCL has a strong reputation internationally in the areas of teaching and research. The institution 
is consistently ranked as being in the top three multi-faculty universities in the U.K. One of the significant distinctions of UCL is its '...embedding of a global perspective in the curriculum, to increase awareness of social justice, environmental responsibility and the challenges of global citizenship'. (UCL, 2008).

University of Manchester, U.K.: The University of Manchester was created in 2004 through the amalgamation of the Victorian University of Manchester and University of Manchester Institute of Science and Technology (UMIST). The University of Manchester has a prestigious reputation both in the U.K. and internationally. Three universities make up the University of Manchester which has over 60,00 students, the largest student population in Europe. It offers teaching and research opportunities in more areas than any other British University. It has a strong research agenda and has received recognition as the leading institution in the field of British Education.

Leeds Metropolitan University, U.K.: Leeds Metropolitan University is one of the largest regional higher education institutions in the U.K. The University was founded in 1824 and consists of two campuses in Headingley and Harrogate with a student cohort of over 52,000. Leeds Metropolitan University offers a wide range of programs of study with teaching practices that are underpinned by a student centred approach which serves to encourage lifelong learning. Central to the university's charter is a commitment to the recruitment and widening participation of students from diverse backgrounds. The institution also has a strong commitment to research and scholarship and has developed centres of research that have regional, national and international emphases.

University of Brighton, U.K.: University of Brighton is a multi-campus institution with a 150 year history located in Brighton, Eastbourne and Hasting. University of Brighton has approximately 21,000 students situated over five campuses. It has a solid research agenda and one of the best teaching quality ratings in the U.K.

\section{Data Collection}

As a means of engaging the four universities in the study the principal researcher contacted personnel within the respective institutions who held key roles focussing on first year transition. Once informed consent was received, the principal researcher facilitated face-to-face in-depth interviews with the key personnel based upon the following research questions:

- What are current key initiatives that serve to enhance the first year experience for students entering the institution?;

- How do these operate within the local context?

- What is the role and function of university personnel working with students in their transition into the university?

- What are the impacts of Griffith University's approaches in enhancing engagement?

\section{Data Analysis}

Qualitative data was organised into key qualitative themes focussing on specific first year strategies and their operation within each respective institution. The themes included: methods that enhance first year engagement; supportive infrastructures including key personnel to assist first year students in their matriculation into university; and overarching institutional approaches that facilitate a more comprehensive approach to the first year experience. Following the identification of key themes, comparisons were drawn between the U.K. initiatives and those 
developed with Griffith University as a means of developing a greater understanding of the scope of activity and relevance to each local context. Quantitative data was derived from a key institutional survey initiated within Griffith University that measures student satisfaction concerning their initial experiences of the university environment. The following section provides an overview of the synthesised data and highlights a range of common factors that align with each university's approach to enhancing the engagement of first year students.

\section{Institution-Wide Orientation and Engagement Strategies that Enhance the First Year Experience}

To date, first year support interventions have tended to be independently facilitated and specifically focused piecemeal efforts that, by their very nature, have been unable to holistically address the multifaceted concerns of first year students (Kift, Nelson \& Clarke, 2010; Kift, 2008; Krause, 2005a; Krause, 2006a; Kuh \& Vesper, 1997). In contrast, an exemplary feature of all the universities under examination is their commitment to integrating services across the whole of the institution. This manifests not only in provision of support for first year students but also in intentional design of curriculum that addresses the interconnected principles of transition, diversity, design, engagement, assessment and evaluation (Kift, Nelson \& Clarke, 2010; Kift, 2009, Krause, 2006b). This section provides a summary of key orientation and engagement strategies specific to the five universities. Common strategies within each institution have been categorized according to the following four areas: orientation week activities; mentoring programs; web-based resources to support student transition; and university support personnel. The following section provides an overview of the various initiatives incorporated as part of the various institutions' approaches to enhancing the first year experience for commencing students.

\section{Orientation Week Activities}

All the institutions under examination include as part of their orientation strategy a comprehensive orientation week program that assists students in their matriculation into the university culture. Leeds Metropoliton University works in partnership with their Student's Union to organize a Freshers' Festival, while at Griffith University each school is responsible for the development of an orientation program and UCL facilitate a Transition Program that focuses on providing specific information. All Universities address the issue of academic preparedness for university, a common key predictor of student retention and success (Davies \& Elias, 2003; Krause, Hartley, James \& McInnes, 2005; Ozga \& Sukhnandan, 1998; Rickson \& Rutherford, 1995). Pre-entry strategies such as those offered at Griffith University, namely, letters of welcome, degree program specific information packages, early bird academic workshops and online just-in-time information and enrolment support assist students to prepare for university before orientation activities begin. Similarly UCL and Leeds Metropolitan University help students to adjust quickly to the new academic demands of studying at university and commit to their new course of study by providing inform-ation sessions on key programs and courses.

In addition to academic preparedness, each of the orientation programs address the social and environmental factors involved with transitioning to university life. Learning to negotiate new environments and rules and forming new relationships constitute an important challenge for students in their first year (Burnett, 2006b, Krause \& Coates, 2008). Successful integration into university culture and the development of authentic, quality relationships between fellow students and staff members encourage a sense of belonging and connectedness in students that promotes ongoing engagement with the university (Palmer, O'Kane and Owens, 2009). 
Socially, events and parties held as part of the Freshers' Festival assist students to settle in to the Leeds Metropolitan culture while students at UCL are encouraged to use the Transition Program to 'make the most of opportunities to meet one another, become involved in campus life and develop their own support networks' (UCL, 2008). The majority of schools at Griffith University facilitate a one to two day intensive face-to-face orientation session during orientation week. These sessions introduce students to school academic and administrative staff as well as key support personnel and centralised support services and serve as an orientation to the school and discipline. Orientation activities aim to assist students to adapt to their new social situation, creating a smooth transition that results in greater likelihood of overall student satisfaction and ultimately degree completion (Burnett, 2006b; Krause, 2005; Tinto, 2002; Vest, 2005; Wilcox, Winn, \& Fyvie-Gauld, 2005; Yorke, \& Thomas, 2003).

Environmentally, orientation activities at all universities provide opportunities for students to familiarise themselves with the campus and services. Sessions at UCL include presentations on: student volunteering; the student union; student rights and advice; the Medical Centre; the Ambassadors Scheme; and Tutoring and Mentoring Programs. Leeds Metropolitan University also focuses on familiarising new students into the University environment with specific events including International Student forums, induction programs and information sessions about key programs and courses, as well as coordinated activities that deepen students' awareness of specific services and supportive infrastructures within the Institution. While a large amount of information is offered throughout these sessions, students are able to 'pick and choose' the topics that are most relevant to them so that information is tailored to the needs of each indi-vidual student. This is scaffolded throughout the semester with 'just-in-time' strategies to address specific concerns as they arise.

Collectively the approaches implemented by each university emphasize the importance of a well organized and detailed orientation week program that coordinates and links specific strategies and processes to facilitate experiences focused on deepening students' connectivity to their peers, their chosen school or faculty, academic and support staff and the broader university culture.

\section{Mentoring Programs}

In a critical review of the literature on mentoring in the university context, factor analysis identified that it served a wide variety of functions that could be classified under two broad categories: psychosocial supports; or academic assistance (Jacobi, 1991; Kram, 1985; Noe, 1988; Olian, Carroll, Giannantonia, \& Feren, 1988; Schockett \& Haring-Hidore, 1985).

At UCL the mentoring process addresses each of these functions in two distinct phases. The first phase takes place in the first five to six weeks of the semester and focuses on psychosocial support by addressing social and personal adjustment issues associated with students' transition into UCL and greater London. In the second half of semester, the second phase is introduced with mentors being available to assist students experiencing academic challenges. Mentoring sessions are designed to be peer-assisted learning opportunities that focus on specific course content. These are conducted in a group context with mentors assuming the role of facilitator. While universities may place differing emphases on the type of mentoring provided, all five incorporated some kind of formal mentoring program which they saw as foundational to the ongoing success and retention of students in their first year of university.

Phase 1 of UCL's mentoring scheme provides support with psychosocial tasks such as: making new friends; developing support networks; developing independence from family; and building a greater awareness of personal needs. Practical assistance is also available for matters such as: organising finances; accommodation and transport; orientation on campus and within London; organising payment of fees; and enrolment. Mentors serve as role models as well as 
normalising first year challenges by sharing some of the experiences they might have faced as UCL students, and insights gained during their course of study.

Similarly, at the University of Brighton mentors, referred to as 'Ambassadors', actively engage students prior to and following entry into the university. Students are welcomed into the school where they will be based, information is disseminated, and advice is given in terms of the students' best interests as opposed to that of the institution (University of Brighton, 2008). Mentors at the University of Manchester, Griffith University and at Leeds Metropolitan University (where mentors are known as 'Student Ambassadors') actively support first year students' transition into university life. This involves playing an intensive role in key events such as open days and orientation week activities. Such mentoring strategies have been demonstrated to increase student retention by fostering relationships between students and the university, which averts obstacles that may otherwise block a student's successful progression beyond the first tertiary year (Burnett \& Larmar, 2011; McGivney, 1996; Wilcox, Winn \& Fyvie-Gauld, 2005).

At Griffith University, academic support is provided by matching second, third and fourth year undergraduate students with commencing undergraduate students. Likewise UCL matches up to 10 students with an experienced student (either second or third year) from the same department. This is in addition to UCL'S specific shift in focus in the second half of the semester from personal adjustment to the general academic challenges associated with each student's study program. Mentoring sessions in the second phase focus on work load, academic skills and assessment. Peer mentoring at the University of Manchester aims to deepen the commencing students' sense of connectedness within their chosen discipline and school with sessions facilitated informally, or linked to faculty-based tutorial groups.

All universities offer training for mentors that is conducted either centrally or locally. While Student Ambassadors from the University of Brighton and mentors at University of Manchester participate in university-wide engagement, they receive training and support from the faculty in which they are located. Griffith's mentor training service is primarily centralised. However, many school-based mentoring strategies have also developed in the last five years as programs are facilitated at both a school and institutional level.

Mentors at UCL receive an initial 150 minute training session which is facilitated prior to the implementation of the Mentoring Scheme. This is complemented by ongoing support from UCL transition program staff throughout the mentoring process. Mentors are also encouraged to email the Transition Project Officer following each meeting with their group of mentees to report on the group's progress. This monitoring ensures that the program maintains its integrity and that mentors and groups are well supported. Each department is invited to participate in the scheme as part of their involvement with the UCL Transition Program. Mentoring activities are facilitated in 31 departments and teaching programs across six faculties and schools. Approximately 1900 students benefit from this initiative annually.

Mentors at UCL are payed approximately 9 pounds per hour (\$14 AUD), for a total of up to 25 hours for their involvement in the mentoring scheme. University of Brighton also remunerate Student Ambassadors for their duties. However, with respect to the other universities, students usually assume the mentor role on a voluntary basis.

On the whole, mentors at each of the universities take steps to engage students by sharing their own university adjustment experiences and providing advice on how first year students can best navigate some of the more common challenges experienced by commencing students. Mentors have regular meetings with students throughout the first term and facilitate or participate in: university open days; campus tours; external visits; first year student induction activities; student question times; first year newsletter input and email contact with interested first year students.

All these strategies serve to improve retention through a coordinated approach that facilitates support prior to entering the university that continues to the end of the student's first year (University of Brighton, 2008). The evidence that these steps promote engagement and success 
and reduce student attrition is clear. Mentoring strategies have been shown to be more effective in increasing retention rates than other strategies in isolation (Gregerman, Lerner, Hippel, Von Jonides, Nagda \& Biren, 1998). In the evaluation of factors associated with attrition, mentoring is highlighted as a factor that has a significant impact upon attrition. The literature clearly indicates that mentoring reduces the likelihood of students leaving the university environment voluntarily (Pascarella \& Terenzini, 2005; Terenzini, Pascarella, Theophilides \& Lorang, 1985; Tinto, 2002)

\section{University Support Personnel}

All universities discussed in this paper incorporated either school/faculty-based or institutionwide support personnel. It is well established that academic staff and support personnel play a key role in students' level of engagement with study and the academic community (Krause, 2005a). Students who receive care and support from staff are more likely to develop academic attitudes that lead to engagement with study (Klem \& Cornell, 2004). Each of the institutions acknowledged the vital role that university support personnel play in providing support and advice for first year students by allocating significant resources to Student Support Tutors, First Year Advisors (FYA), Student Liaison Officers and Sabbaticals. For example, the Teaching and Learning Support Office at The University of Manchester has a primary focus on the first year experience providing advice, information and support. The Office works with the University's Vice President for Teaching and Learning, as well as with faculties, schools and other administrative offices. One of the key arms of the Teaching and Learning Support Office is the 'Students as Partners' initiative that serves to assist in:

- partnering students with staff in programs of study;

- promoting and supporting innovative ways of teaching; and

- assessing students and helping them to manage their own learning (www.campus.manchester. ac.uk/tlso/).

- The 'Students as Partners' scheme primarily utilises the following initiatives:

- peer mentoring;

- sabbatical personnel; and

- Peer Assisted Study Sessions (PASS).

A key initiative birthed out of the work of the Teaching and Learning Support Office is the sabbatical position. Recent graduates of the University undertake the sabbatical position and align with one of the four faculties in a full-time capacity across the academic year. Throughout their tenure they work closely with Teaching and Learning Support Office personnel who provide intensive supervision and support for staff and students. The key roles of the sabbatical include:

- supporting student-led initiatives within the respective faculty, maintaining regular contact with Coordinators and facilitating PASS sessions;

- undertaking managerial responsibilities in the implementation and/or evaluation of facultybased schemes and initiatives; and

- facilitating a network of good practice which means liaising with students and/or academic staff (Odey \& Carey, 2008).

Student Support Tutors at the University of Brighton actively serve to deepen the student's connection through the facilitation and coordination of strategies leading up to and prior to a student's actual enrolment in tertiary study. These strategies include pre-entry newsletters, induction of student ambassadors, participation and coordination of activities for University Open days and visits, campus tours, and connecting with prospective students' parents. Student 
Support Tutors and Student Liaison Officers at Leeds Metropolitan University work with academic staff to offer guidance, advice and support to assist students as they adjust to university life and progress through their program of study. They maintain a visible presence in the school, connect students to support services offered within the university, liaise with such services to ensure students receive the necessary support and/or advice and are also available by drop-in appointment to discuss issues that may arise. Student Liaison Officers are faculty-based, fulltime positions and the role has a complete focus on the provision of student support.

The effectiveness of university support personnel has been exemplified by Griffith University, who established the role of the FYA as an institution wide initiative in 2005 (Burnett \& Larmar, 2008). As part of Griffith University's commitment to enhancing the first year experience, a number of university-administered surveys were administered to measure the effectiveness of such initiatives on: student engagement; information acquisition; organisation; connectivity; knowledge of university staff and services; disciplinary engagement; sense of capability; sense of purpose; sense of connectedness; and overall satisfaction (Larmar \& Ingamells, 2010). Results revealed that each of these factors were improved by the engagement strategies and in particular showed the effectiveness of university support personnel in promoting overall engagement. Each school at Griffith University has an appointed FYA who is drawn from the appropriate school's academic staff with a specific work load formula which comprises research and teaching commitments in concert with FYA responsibilities. Such responsibilities include leadership of school-based orientation and engagement activities and coordinated support across the school's first year community. The FYA role is supported by the Student Experience Coordinator. The Coordinator works across the institution, collaborating with FYAs to assist them in their responsibilities at a school level.

In support of Griffith's findings, the AUSSE survey conducted by Kuh (2004) indicates that students' perceptions of the quality of academic advising are positively correlated with higher order mental activities that help students succeed in higher education. Australian undergraduates are more likely to report higher levels of achievement, more satisfaction with their course and a clear intention to continue in tertiary education when they are engaged with academics and the institution (Krause, 2005a). Students reporting factors that are important at their university indicate that a positive relationship can be found between academic factors and supportive relationships with staff (Kuh, 2004). In response to the clear evidence supporting the use of student support personnel to promote engagement, each of the universities has implemented interventions that have been successful in achieving these ends.

\section{Web-based Resources to Support Student Transition}

Web-based resources have transformed higher education in the last decade. Many courses are now facilitated online and almost all traditionally facilitated subjects have some online component (Brown \& Lippincott, 2003). More than 97\% of students report using the web for study purposes, and first year students are spending an average of 4.2 hours a week using the web for study, in addition to the time spent in classes and private study (Krause, 2005a). As universities become increasingly reliant on the internet for the delivery of services, the strategies they use to engage students will need to adjust to the changing environment by including more webbased resources to support student transition.

The institutions investigated in this paper utilise web resources as part of their overall engagement strategies. Griffith’s Commencing@Griffith First Year Website, University of Brighton's Studentcentral, and University College London's Transition Website demonstrate the important role web resources play in promoting student engagement. Each of these online student portals provides access to a range of learning resources and connect students to the university at large. Online services may include access to library resources, a community space promoting social networks, a site devoted to the provision of information for students prior to their arrival to 
help them in preparing for their studies, and electronic discussion forums to assist in the development of student networks. At UCL, forums focus on key issues impacting commencing students' assimilation into the University culture. Leeds Metropolitan University places student information points called Helpzones in strategic positions across its campuses. These serve to assist students to discover relevant information related to their study and university life. The Helpzones also act as points of referral for students seeking specialist support such as student counseling services or International Student Advisors. Each Helpzone location consists of a suite of computers where students can go to access their email or the Helpzone website. The Helpzone website is a comprehensive hub that provides students with a web-based directory that assists individuals to access key information relevant to their engagement as students.

None of the universities relied upon web-based resources alone but rather used them to complement broader, multifaceted strategies that often emphasized the dissemination of information through interpersonal channels. However as trends continue to show higher education institutions increasingly adopting online practices, students are likely to conduct an increasing amount of their academic activities off campus (Allen \& Seaman, 2008). While research suggests that online resources are not a substitute for effective face to face teaching and learning (Krause, 2005a) the possibility that they may well become the primary means of engaging students with their faculty needs to be addressed. Krause (2005b) recommends that the community-building capacities of online forums be used to connect students to the learning community and to each other. The provision of 'consumer friendly' intranet sites by each of the universities recognizes and addresses this issue. Student websites that include comprehensive information about the university culture, first year advice and relevant knowledge about studying at university, links to relevant services available to first year students, and discussion forum sites to foster a deeper sense of community are considered pertinent to orienting and engaging students both now and in the future.

This section has provided an overview of key initiatives specific to each university included in the investigation. Discussion also focused on common factors that were shared across each institution that assisted in the matriculation of students into each respective institution. The following section provides a summary of retention data specific to Griffith University that reinforces the validity of the various strategies incorporated as part of each institution's overarching commitment to deepening engagement of first year students.

\section{Impacts of Strategies on the Retention and Engagement of Students for Griffith University}

The following section provides data that highlights the positive influences of Griffith's approaches to student satisfaction. The focus on this data was influenced by the key researcher's capacity to access Griffith University reports based on the first year experience across the institution. A significant limitation of the research centered on the lack of access to quantitative data from the U.K. institutions under investigation. For this reason, qualitative methods were primarily employed to develop comparisons between the approaches across the five universities. The quantitative Griffith data was drawn from an institution based survey first implemented in 2005. The survey is titled Starting@Griffith and consists of 40 items. The survey is administered online to commencing students within the University between weeks four and seven of their first semester that takes approximately 15 minutes to complete. The data is organized according to three overarching scales. The scales and overall results are presented in the following table (Table One). 
Table One

Scale 1 Engagement in Program Griffith, Academic Groups and Campuses

\begin{tabular}{|l|c|c|c|c|c|c|c|c|c|}
\hline & $\mathrm{N}$ & Mode & Mean & SD & Agree & Neutral & Disagree & 2010 & 2011 \\
\hline GRIFFITH & 3958 & 4 & 3.9 & 0.83 & $72.1 \%$ & $22.0 \%$ & $5.9 \%$ & $0.9 \%$ & $2.2 \%$ \\
\hline Domestic & 3404 & 4 & 3.9 & 0.83 & $73.5 \%$ & $20.8 \%$ & $5.8 \%$ & $1.7 \%$ & $2.9 \%$ \\
\hline International & 553 & 4 & 3.7 & 0.84 & $63.8 \%$ & $29.8 \%$ & $6.5 \%$ & $0.0 \%$ & $0.2 \%$ \\
\hline
\end{tabular}

Scale 2 Know and Interact with Staff and Students

\begin{tabular}{|l|c|c|c|c|c|c|c|c|c|}
\hline & $\mathrm{N}$ & Mode & Mean & $\mathrm{SD}$ & Agree & Neutral & Disagree & 2010 & 2011 \\
\hline GRIFFITH & 3947 & 4 & 3.7 & 1.00 & $65.5 \%$ & $20.2 \%$ & $14.3 \%$ & $-0.8 \%$ & $0.7 \%$ \\
\hline Domestic & 3395 & 4 & 3.7 & 1.00 & $67.5 \%$ & $18.7 \%$ & $13.8 \%$ & $0.6 \%$ & $1.6 \%$ \\
\hline International & 553 & 4 & 3.5 & 0.98 & $53.2 \%$ & $30.0 \%$ & $16.8 \%$ & $-4.3 \%$ & $-2.4 \%$ \\
\hline
\end{tabular}

Scale 3 Effectiveness of Orientation Griffith, Academic Groups and Campuses

\begin{tabular}{|l|c|c|c|c|c|c|c|c|c|}
\hline & $\mathrm{N}$ & Mode & Mean & SD & Agree & Neutral & Disagree & 2010 & 2011 \\
\hline GRIFFITH & 3438 & 4 & 3.7 & 0.88 & $68.4 \%$ & $22.2 \%$ & $9.4 \%$ & $-1.4 \%$ & $0.5 \%$ \\
\hline Domestic & 2984 & 4 & 3.8 & 0.88 & $69.9 \%$ & $21.0 \%$ & $9.1 \%$ & $-0.3 \%$ & $0.9 \%$ \\
\hline International & 454 & 4 & 3.6 & 0.85 & $58.5 \%$ & $30.3 \%$ & $11.2 \%$ & $-6.3 \%$ & $-0.9 \%$ \\
\hline
\end{tabular}

Staff-student relationship-Griffith, Academic Groups and Campuses

\begin{tabular}{|l|c|c|c|c|c|c|c|c|c|}
\hline & $\mathrm{N}$ & Mode & Mean & $\mathrm{SD}$ & Agree & Neutral & Disagree & 2010 & 2011 \\
\hline GRIFFITH & 3954 & 4 & 3.8 & 0.83 & $71.8 \%$ & $21.6 \%$ & $6.5 \%$ & $0.8 \%$ & $3.3 \%$ \\
\hline Domestic & 3402 & 4 & 3.9 & 0.83 & $73.2 \%$ & $20.4 \%$ & $6.4 \%$ & $1.7 \%$ & $4.2 \%$ \\
\hline International & 553 & 4 & 3.7 & 0.84 & $63.4 \%$ & $29.4 \%$ & $7.2 \%$ & $-0.9 \%$ & $-0.7 \%$ \\
\hline
\end{tabular}

Good Teaching

\begin{tabular}{|l|c|c|c|c|c|c|c|c|c|}
\hline & $\mathrm{N}$ & Mode & Mean & $\mathrm{SD}$ & Agree & Neutral & Disagree & 2010 & 2011 \\
\hline GRIFFITH & 3958 & 4 & 3.9 & 0.84 & $73.3 \%$ & $20.3 \%$ & $6.4 \%$ & $1.5 \%$ & $3.9 \%$ \\
\hline Domestic & 3404 & 4 & 3.9 & 0.84 & $74.6 \%$ & $19.1 \%$ & $6.3 \%$ & $2.5 \%$ & $4.8 \%$ \\
\hline International & 554 & 4 & 3.7 & 0.83 & $65.3 \%$ & $27.5 \%$ & $7.2 \%$ & $-1.3 \%$ & $-0.5 \%$ \\
\hline
\end{tabular}

Sense of Connection-Griffith, Academic Groups and Campuses

\begin{tabular}{|l|c|c|c|c|c|c|c|c|c|}
\hline & $\mathrm{N}$ & Mode & Mean & $\mathrm{SD}$ & Agree & Neutral & Disagree & 2010 & 2011 \\
\hline GRIFFITH & 3960 & 4 & 3.7 & 0.80 & $66.5 \%$ & $27.2 \%$ & $6.3 \%$ & $1.5 \%$ & $3.2 \%$ \\
\hline Domestic & 3407 & 4 & 3.8 & 0.80 & $68.6 \%$ & $25.4 \%$ & $6.0 \%$ & $2.9 \%$ & $4.0 \%$ \\
\hline International & 553 & 4 & 3.5 & 0.80 & $53.6 \%$ & $38.5 \%$ & $7.8 \%$ & $-1.4 \%$ & $1.2 \%$ \\
\hline
\end{tabular}




\begin{tabular}{|c|c|c|c|c|c|c|c|c|c|}
\hline \multicolumn{10}{|c|}{ Sense of Capability } \\
\hline & $\mathrm{N}$ & Mode & Mean & SD & Agree & Neutral & Disagree & 2010 & 2011 \\
\hline GRIFFITH & 3961 & 4 & 3.7 & 0.82 & $63.6 \%$ & $29.2 \%$ & $7.2 \%$ & $2.8 \%$ & $2.7 \%$ \\
\hline Domestic & 3407 & 4 & 3.7 & 0.82 & $63.9 \%$ & $28.7 \%$ & $7.4 \%$ & $3.0 \%$ & $2.8 \%$ \\
\hline International & 554 & 4 & 3.7 & 0.83 & $61.8 \%$ & $32.0 \%$ & $6.2 \%$ & $2.0 \%$ & $3.3 \%$ \\
\hline \multicolumn{10}{|c|}{ Sense of Purpose-Griffith, Academic Groups and Campuses } \\
\hline & $\mathrm{N}$ & Mode & Mean & SD & Agree & Neutral & Disagree & 2010 & 2011 \\
\hline GRIFFITH & 3957 & 4 & 4.0 & 0.83 & $79.3 \%$ & $16.3 \%$ & $4.4 \%$ & $-1.3 \%$ & $-0.1 \%$ \\
\hline Domestic & 3403 & 4 & 4.1 & 0.83 & $80.3 \%$ & $15.3 \%$ & $4.3 \%$ & $-0.9 \%$ & $0.3 \%$ \\
\hline International & 553 & 4 & 3.9 & 0.85 & $72.7 \%$ & $22.5 \%$ & $4.8 \%$ & $1.9 \%$ & $-1.2 \%$ \\
\hline \multicolumn{10}{|c|}{ Overall Satisfaction } \\
\hline & $\mathrm{N}$ & Mode & Mean & SD & Agree & Neutral & Disagree & 2010 & 2011 \\
\hline GRIFFITH & 3957 & 4 & 4.0 & 0.81 & $78.1 \%$ & $17.5 \%$ & $4.3 \%$ & $0.0 \%$ & $0.3 \%$ \\
\hline Domestic & 3404 & 4 & 4.0 & 0.80 & $80.2 \%$ & $15.7 \%$ & $4.1 \%$ & $1.2 \%$ & $1.2 \%$ \\
\hline International & 553 & 4 & 3.8 & 0.83 & $65.6 \%$ & $28.8 \%$ & $5.6 \%$ & $-0.1 \%$ & $-3.3 \%$ \\
\hline
\end{tabular}

Scale one reported a modest increase in terms of perceptions relating to program engagement with all academic groups maintaining consistent scores over time with some elements indicating some improvement. Scale two indicated a slight decline from previous years in terms of student knowledge of and interaction with staff. However, the overall score of $65 \%$ agreement represents a significant $13 \%$ improvement from 2006-2011, reflecting Griffith's steady commitment to facilitating engagement with staff that is student centred and socially inclusive. Finally, scale three reporting on perceptions relating to the effectiveness of orientation revealed that $68 \%$ of students across the institution either agreed or strongly agreed that the orientation experience assisted in their matriculation into the university environment. This data reinforces the significant influences of the various institution-wide strategies outlined above in enhancing the first year experience for students matriculating to Higher Education.

\section{Limitations}

There were a number of limitations inherent in the study. Given that the researcher was situated in a particular geographic location in the U.K. the targeted universities were in part selected on the basis of convenience. Further research should consider the inclusion of other institutions that parallel characteristics within Griffith University such as student demographics, program offerings and orientation and engagement strategies to enhance first year engagement. The focus on Griffith data highlighting student perceptions of the early learning environment was another limitation of the research. This limitation was influenced by the insufficient access to quantitative data focusing on the institutions included in the research. Future investigations should consider the inclusion of both qualitative and quantitative data focusing on student attrition and specific student perceptions about their experiences in each respective institution. Finally, the findings are limited to data that was collected at one time point. The study would have been enhanced through the inclusion of data collected longitudinally. 


\section{Conclusion}

This paper has provided examples of individual institutional approaches to engaging first year students. Each of the institutions investigated is recognized for the effectiveness of its interventions, its strategic focus on the experience of first year students including planning, development and implementation of strategies to improve first year student retention. Comparisons were drawn across five institutions to determine emergent themes of best practice within the first year experience. While it was evident that each university had developed strategies tailored to the local context, all institutions reported on the effectiveness of a formal orientation program and related strategies including: student mentoring; academic skills workshops; student community forums; web-based support initiatives (including first year websites), and key first year personnel responsible for the coordination of university, faculty and/or school-based support for first year students. Key personnel within each institution reported on the significance of the first year experience and acknowledged that their particular university was committed to investing considerable resources to make the first year experience useful and relevant to commencing students. The collective effectiveness of these interventions clearly aligns with the international literature on student retention and engagement (Burnett, 2007; Burnett \& Larmar, 2011; Kift, Nelson \& Clarke, 2010; Kift, 2008; Krause, 2005a; Kuh \& Vesper, 1997; Tinto, 2002; Wilcox, Winn \& Fyvie-Gauld, 2005). A summary of quantitative data from Griffith University was also represented that highlighted the impacts of an institutional approach to effectively engaging and orientating first year students. Finally, findings drawn from the exploration of the key institutions under investigation emphasized the significance of a coordinated and strategic institutional approach to the orientation and engagement of first year students as a means of facilitating more holistic approaches that widen participation.

\section{Acknowledgments}

The authors wish to acknowledge the significant contributions of Dr. Marco Angelini of UCL, Ms. Marcia Odey and Mr William Carey of University of Manchester, Ms. Ruth Pickford of Leeds Metropolitan University, Ms. Marilyn Doust and Dr. Gillian Lines of the University of Brighton and Mr. Stephen Lewis-Driver, Griffith University in the development of this paper. 


\section{REFERENCES}

Allen, I., and Seaman, J. 2008, Staying the Course: Online Education in the United States. Needham MA: Sloan Consortium

Brown, M.B., and Lippincott, J.K. 2003 "Learning Spaces: More than Meets the Eye," Educause Quarterly, 26: 14-16

Burnett, L. 2007. “Juggling First Year Student Experiences and Institutional Changes: An Australian Experience.” Paper presented at the $20^{\text {th }}$ International Conference on First Year Experience, Hawaii, USA, July 9-12.

Burnett, L. 2006a. The First Year Experience Report . Brisbane: The University of Queensland. Burnett, L. 2006b. "FIRST: Finding the "I". Revealing Students' Tensions and Experiences During Their First Year at the University of Queensland." Paper presented at the $9^{\text {th }}$ International First Year in Higher Education Conference, Brisbane, Australia, July 12-14.

Burnett, L., and Larmar, S.A. 2011, "Improving the First Year Through an Institution-Wide Approach: The Role of the First Year Advisors." International Journal of the First Year Experience in Higher Education, 1: 21-35.

Burnett, L. 2008. Improving the First Year: The Role of First Year Advisors (FYAs). Paper presented at $21^{\text {st }}$ International Conference on the First Year Experience, Dublin, June 23-26.

Clark, E., and Ramsey, W. 1990, "Problems of Retention in Tertiary Education," Education Research and Perspectives, 17: 47-59.

Davies, R., and Elias, P. 2003. Dropping Out: a Study of Early Leavers from Higher Education. Department for Education and Skills: London.

Gabb, R., Milne, L. and Zhongjun, C. 2006, "Understanding Student Attrition, A Review of Recent Literature." Paper presented at Postcompulsory Education Centre, Melbourne University, Australia, January 31.

Gerdes, H., and Mallinckrodt, B. 1994. "Emotional, Social, and Academic Adjustment of College Students: A Longitudinal Study of Retention," Journal of Counselling and Development, 72: 281-288.

Harris, N., and Palmer, A. 1995. "Doing More with Less, Improving the Quality of the First Year Experience on Business Undergraduate Courses Within the Context of a Diminishing Resource Base," Journal of Further \& Higher Education, 19: 63-73.

Jacobi, M. 1991. "Mentoring and Undergraduate Academic Success: A Literature Review." Review of Educational Research, 61: 505-532.

Kift, S.M., Nelson, K., and Clarke, J. 2010. "Transition Pedagogy: A Third Generation Approach to FYE-a Case Study of Policy and Practice for the Higher Education Sector." International Journal of the First Year Experience in Higher Education, 1: 1-20.

Kift, S. M. 2008. "The Next, Great First Year Challenge: Sustaining, Coordinating and Embedding Coherent Institution-Wide Approaches to Enact the FYE as "Everybody's Business"." Paper presented at the $11^{\text {th }}$ International Pacific Rim First Year in Higher Education Conference, An Apple for the Learner: Celebrating the First Year Experience, Hobart, June 30-July 2.

Kift, Sally M., and Field, Rachel. 2009. "Intentional First Year Curriculum Design as a Means of Facilitating Student Engagement: Some Exemplars," Paper presented at the $9^{\text {th }}$ International First Year in Higher Education Conference, Brisbane, Australia, July $12-14$.

Klem, Adena M., and James P. Connell. 2004. "Relationships Matter: Linking Teacher Support to Student Engagement and Achievement." Journal of School Health. 74: 262-273.

Kogan, M., and Hanney, S. 2000. Reforming Higher Education, London: Jessica Kingsley Publishers. 
Kram, K. E. 1985. Mentoring at Work: Developmental Relationships in Organizational Life. Glenview, IL: Scott, Foresman \& Co.

Kuh, G., and Vesper, N. 1997. "A Comparison of Student Experiences with Good Practices in Undergraduate Education Between 1900 and 1994." The Review of Higher Education, 21: 43-61.

Krause, K.L. 2006a. "Transition to and Through the First Year: Strategies to Enhance the Student Experience.” Paper presented at the University of the Sunshine Coast Inaugural Vice Chancellor's Learning and Teaching Colloquium, May 31.

Krause, K.L., 2006b. "On Being Strategic About the First Year.” Keynote Address at the Queensland University of Technology First Year Forum, Brisbane, Australia, July 12.

Krause, K.L. 2005a. Understanding and Promoting Student Engagement in University Learning Communities. Melbourne: CSHE.

Krause, K.L. (2005b). “The Changing Student Experience: Who's Driving it and Where is it Going?” Keynote paper presented at Student Experience Conference: Good Practice in Practice. Charles Sturt University, Wagga Wagga, New South Wales, September $5-7$.

Krause, K.L., Hartley, R., James., and McInnes, C. 2005. The First Year Experience in Australian Universities: Findings from a Decade of National Studies. University of Melbourne: CHSE.

Krause, K.L., and Coates, H. 2008. "Student Engagement in First-Year University, Assessment and Evaluation in Higher Education, 33: 493-505.

Kuh, G. D. 2000. The National Survey of Student Engagement: Conceptual Framework and Overview of Psychometric Properties. Bloomington: Indiana University Center for Postsecondary Research and Planning.

Kuh, G. D., Kinzie, J., Buckley, J., Bridges, B., and Hayek, J. C. 2006. What Matters to Student Success: A Review of the Literature. Bloomington: Indiana University Center for Postsecondary Research.

Larmar, S.A. , and Ingamells , A. 2010. "Enhancing the First-Year University Experience: Linking University Orientation and Engagement Strategies to Student Connectivity and Capability," Research in Comparative and International Education, 5: 210223.

Lizzio, A., and Wilson, K. 2004. "First-Year Students' Perceptions of Capability," Studies in Higher Education, 29: 109-128.

Lowe, H., and Cook, A. 2003. "Mind the Gap: Are Students Prepared for Higher Education," Journal of Further and Higher Education, 27: 53-76.

McGivney, V. 1996. "Staying or Leaving the Course, Adults Learning, 7: 133-135.

McInnes, C. 2001. Signs of Disengagement? The Changing Undergraduate Experience in Australian Universities. Victoria: University of Melbourne.

McInnes, C., James, R., and Hartley, R. 2000. Trends in the First Year Experience in Australian Universities. Canberra: AGPS.

McInnes, C., and James, R. 1995. First Year On Campus: Diversity in the Initial Experiences of Australian Undergraduates. Canberra: AGPS.

McInnes, C. and Hartley, R. 2002. "Managing Study and Work," Accessed January 15. http/l www.dest.gov.au

Mc Kenzie, K., and Schweitzer, R. 2001. "Who Succeeds at University? Factors Predicting Academic Performance in First Year Australian University Students," Higher Education Research and Development, 20: 21-33.

McMillan, J. 2005. Course Change and Attrition from Higher Education, Camberwell: Australian Council for Educational Research.

Noe, R. A. 1988. "Women and Mentoring: A Review and Research Agenda," Academy of Management Review. 13: 65-78. 
Nunan, T. 1999. “Graduate Qualities, Employment and Mass Higher Education.” Paper delivered at the HERDSA (Higher Education Research \& Development Society of Australasia) Annual International Conference, Melbourne, July 12-15.

Olian, J.D., Carroll, S.J., Giannantonia, C.M., and Feren, D.B. 1988. "What Do Protégés Look for in a Mentor? Results of Three Experimental Studies," Journal of Vocational Behavior. 33:15-37.

Ozga, J. and Sukhnandan, L. 1998. "Undergraduate Non-Completion: Developing an Explanatory Model," Higher Education, 52: 316-333.

Palmer, M., O'Kane, P., and Owens, M. 2009. "Betwixt Spaces: Student Accounts of Turning Point Experiences in the First-Year Transition," Studies in Higher Education, 34: 37-54.

Pascarella, E. T., and Terenzini, P. T. 2005. How College Affects Students: A Third Decade of Research, San Francisco: Jossey-Bass.

Pike, G.R., and Kuh, G.D. 2005. "First and Second Generation College Students: A Comparison of their Engagement and Intellectual Development," Journal of Higher Education, 76: 3-28.

Pitkethly, A., and Prosser, M. 2001. "The First Year Experience Project: A Model for UniversityWide Change," Higher Education Research and Development, 20: 185-198.

Ramsden, P. 2003. Learning to Teach in Hgher Education ( $2^{\text {nd }}$ edn), London: Routledge Falmer.

Reay, D. 1998). “'Always Knowing' and 'Never Being Sure': Familial and Institutional Habituses and Higher Education Choice," Journal of Education Policy, 13: 519-529.

Rickinson, B., and Rutherfod, D. 1995. "Increasing Undergraduate Student Retention Rates," British Journal of Guidance and Counseling, 23: 161-172.

Schockett, M.R., and Haring-Hidore, M. 1985. "Factor Analytic Support for Psychosocial and Vocational Mentoring Functions," Psychological Reports, 57: 627-630.

Terenzini, P.T., Pascarella, E.T., Theophilides, C., and Lorang, W.G. 1985. "A Replication of a Path Analytic Validation of Tinto's Theory of College Student Attrition," Review of Higher Education, 8: 319-340.

Tinto, V. 2002. "Promoting Student Retention: Lessons Learned from the United States." Paper presented at the $11^{\text {th }}$ Annual Conference of the European Access Network, Prato, Italy June 19-22.

Vest, C. M. 2005. Pursuing the Endless Frontier: Essays on MIT and the Role of Research Universities. Cambridge, MA: The MIT Press.

Wilcox, P., Winn, S., and Fyvie-Gauld, M. 2005. "'It Was Nothing to do with the University, It Was Just the People': The Role of Social Support in the First-Year Experience of Higher Education," Studies in Higher Education, 30: 707-722

Yorke, M. with Bell, R., Dove, A., Haslam, L., Hughes Jones, H., Longden, B., O’Connell, C., Typszak, R., and Ward, J. 1997. Undergraduate Non-Completion in England. HEFCE: Bristol.

Yorke, M., and Longden, B. (2008). The First-Year Experience of Higher Education in the UK: Final report. Higher Education Academy: U.K.

Yorke, M., and Thomas, L. 2003. "Improving the Retention of Students from Lower SocioEconomic Groups," Journal of Higher Education Policy and Management, 25: 63-74. 


\section{ABOUT THE AUTHORS}

Dr. Stephen Anthony Larmar: Stephen is a senior lecturer with the School of Human Services and Social Work at Griffith University. For the past 9 years at Griffith, he has lectured primarily in the areas of counseling and introductory psychology. His current research includes investigation of conduct problems in children and adolescents, child mentoring as an early intervention and prevention framework, managing challenging behaviours in children and adolescents in out-of-home care, and the retention and engagement of first year university students. As well as teaching and research, he also serves as the first year advisor of the School of Human Services and Social Work, where he leads and coordinates orientation and engagement activities to assist first year Human Services and Social Work students with university integration. In addition to his work with Griffith University, Stephen has also spent the last 10 years providing professional supervision for counselors and psychologists working in both government and non-government settings.

Dr. Lynn Burnett: 

The International Journal of Learning in Higher Education is one of ten thematically focused journals in the family of journals that support The Learner knowledge community-its journals, book series, conference and online community. It is a section of The International Journal of Learning.

The journal offers studies of learning at college and university levels, including teacher education.

As well as papers of a traditional scholarly type, this journal invites presentations of practice-including documentation of higher education practices and exegeses of the effects of those practices.

The International Journal of Learning in Higher Education is a peer-reviewed scholarly journal.

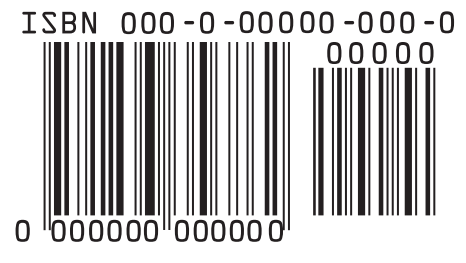

